\title{
Proactive interviewing
}

\author{
By Debra R. Biggs \\ Reference/Instruction Librarian \\ Undergraduate Library, University of Michigan
}

and Cheryl T. Naslund

Head, Information Services

Creare, Inc., Hanover, N.H.

\section{Strategies for the assertive job hunt.}

I nterviewing for a position provides an opportunity for the prospective employee and the employer to maximize the mutual benefit or match between employee and organization. The dynamics of interviewing are complex, and the possibility of subsequent interviews further enhances the need for an organized and comprehensive approach to exploring a potential match. Although numerous articles and books have been written on how to interview, how to find a job, and what to do with the rest of one's life, most interview suggestions focus on interviewing on the defensive, on what to expect in an interview and how to respond to the interviewer. With the high financial and emotional costs associated with position changes, few job applicants can afford to, nor should they ignore, their need for a satisfactory match. The authors of this paper will therefore focus on interviewing from the candidate's perspective by taking a proactive, assertive position toward making crucial decisions about the future.

The interview is a candidate's prime opportunity to demonstrate marketing skills; it provides the setting in which to project a memorable image and to communicate style and personality. The candidate should keep in mind that " $85 \%$ [of the verbal content] of the interview will be forgotten within an hour of [the interviewee's] departure," leaving only the overall impression, the documents submitted and possibly a few notes. ${ }^{1}$

As an applicant you must remember to personal-

\footnotetext{
'Jeffrey G. Allen, How to Turn an Interview Into a Job (New York: Simon and Schuster, 1983), 49 .
}

ize the interview to enhance your staying power in the interviewer's mind. This is as important in group interviews where the candidate is meeting a number of staff members in a single session as it is in interviews with an individual interviewer. Throughout this article, we will use the term "interviewer" generically, indicating both individual and group interview situations.

\section{Interview preparation}

There is no question that preparation prior to an interview is crucial in terms of forming a knowledge base from which to conduct the interview. Doing one's "homework" on the organization will provide a preliminary sense of the library's structure and operation. Once the interview date has been set, a packet of materials describing the library and its environment should be sent to each candidate; all too frequently, however, this is not the case. If a candidate does not receive any information, a request should be made for such documentation as library publications, annual reports, organizational charts, policies and procedures, staff manuals, and, of course, the job description for the position in question. Access to these kinds of documents prior to the interview allows the candidate to develop an informed understanding of the institution and a basis upon which to evaluate it.

Interview experts frequently advise further sleuthing: "Once you have learned about the library from published sources, begin making telephone calls to your friends. Learn as much as you can about the managerial style of the dean or direc- 
tor and the conditions of employment."2 The interviewee's ability to do the above is clearly contingent on available resources, i.e. who one knows or who one can identify through close contacts. Walking into the interview with pertinent background information will enable the candidate to talk intelligently with the interviewer about the library in addition to telling the interviewer that he/she is sufficiently interested in the organization and the position to have done some research ahead of time. The interviewer will undoubtedly be impressed. ${ }^{3}$

\section{Interview mindset}

This is just the beginning in developing a constructive approach to interviewing. During the factual preparation for the interview, the candidate also needs to start creating a positive interviewing mindset. It is not productive to look at the interview as The Great Confrontation. Instead, it is essential to "recognize [the interview for] what it really is: an informal chat to determine if your background fits into the [library's] needs to your mutual satisfaction." It is important to remember that the library is interested in you and has given you the opportunity to take a close look at it as well; a subservient "I want this job" kind of attitude is of no use here. ${ }^{5}$

Interviewing from the candidate's perspective is a critical proactive exercise because it turns the tables, giving the candidate the opportunity to ask the questions and to interview the interviewer. At this point, the interviewer should endeavor to sell the library. Based on the candidate's questions, the interviewer can comment on, for example, what kind of relationship there exists between the library, the faculty, the administration; what kind of change has occurred within the organization over the past five years; what makes the library a challenging and enjoyable place to work. The interviewer's ability to promote the library in a conversational format will provide both parties a mutual means of evaluating the entire experience. ${ }^{6}$ This also injects a spirit of equality into the situation that precludes the "deferential, petitionary" role of the overly traditional job applicant. Richard Irish, in his book Go Hire Yourself an Employer, advocates an honest approach to interviewing, "by simply being yourself, asking unexpected questions, interviewing your interlocutor (asking him about his job); in a word, treating your em-

\footnotetext{
${ }^{2}$ Margo C. Trumpeter, "The Job Interview," College \& Research Libraries 41 (May 1980):139-40.
}

${ }^{3}$ Billy R. Wilkinson, "Recruitment and Selection," in Personnel Administration in Libraries, ed. Sheila Creth and Frederick Duda (New York: Neal-Schuman Publishers, 1981), 111.

${ }^{4}$ Dorrine Anderson Turecamo, "Would You Hire Yourself? Guidelines for a Successful Interview," Supervision 45 (February 1983):3-5, 23.

${ }^{5}$ Ibid, 3.

"Wilkinson, "Recruitment and Selection," 110. ployer as an equal." In this way you will be better able to make the all-important decision of whether or not you want to work for the library. ${ }^{7}$

Using an honest approach in presenting oneself to the interviewer is of course important in answering the questions posed; a bluff is easily spotted by an experienced employer. ${ }^{8}$ Your ability to ask straightforward, insightful questions, however, allows the interviewer to view your perspective and concerns; it also serves to mirror "your judgment, analytical ability, and seriousness about this most important decision"- that is, sizing up the library for the best possible fit. Furthermore, you need to find out whether the job is really what the library claims it is, and whether the job really meets your needs. ${ }^{9}$

\section{Interview question design}

Preparing interview questions in a proactive manner can be easily accomplished by categorizing the important aspects of a position and its institutional climate. A candidate should prepare a personal and prioritized needs assessment. What aspects of employment are important to your relationship with the job as well as the library/organization? Are you, or, indeed, should you be concerned about how you will fit in with the administrative structure and style of the library? Is there a well established financial base for the library? What kind of communication and authority structure is in place? Given the burgeoning technology of our information society, to what extent is the library automated, or is it at least planning for that eventuality? How are librarians evaluated? Do you have a detailed description of the position for which you are applying? Of what is the benefits package comprised?

Applicants should consider the host of major issues from both a formal and informal perspective. The facts of a given position are important, but the impact of the atmosphere and/or social climate/ culture of the job should not be underestimated. Analyze the interviewer's responses both from a verbal and nonverbal perspective. Your body language will be observed during the interview; turn the tables and benefit from observing nonverbal communication on the interviewer's part. It is wise to remember that the fit you seek between yourself and the job should be holistic. Not only should you consider the development of your professional life, but you also need to be knowledgeable about how both the workplace and community environment will impact your personal life.

${ }^{7}$ Richard K. Irish, Go Hire Yourself an Employer (Garden City, N.Y.: Anchor Press/Doubleday, 1973), 68 .

Ibid, 69.

${ }^{9}$ Sigmund G. Ginsburg, "Preparing for Executive Position Interviews: Questions the Interviewer Might Ask-or Be Asked," Personnel 57 (JulyAugust 1980):31-36 . 
With attention to each of these broad conceptual areas in mind, the interviewee can begin to formulate a checklist of indepth questions to take to the interview. Many of these questions can and should be answered in the conversational flow of the interview, often not specifically at the candidate's request. The exercise of preparing thoughtful questions in advance will allow the interviewee to analyze the kind of information needed to make a critical decision-based on measurable criteria about how well the job fits personal needs, goals, and objectives.

\section{Interview form and style}

Interviewing consists of a volley of questions and answers. An applicant should consider carefully how to phrase the prepared questions. The candidate should also be aware that the interviewer may not be accustomed to or comfortable with more than the perfunctory questions traditionally being asked by job applicants. In no way should the interviewer be made to feel that he/she is on the firing line. Rather, queries can be made in the spirit of genuine interest, designed to help one make decisions about the position while communicating concerns to the interviewer. Hopefully the interviewer will not adopt a defensive attitude at questions sincerely posed. Alfred Benjamin, in his book The Helping Interview, advises interviewers that "once we see the question as one of the ways in which the interviewee expresses himself, we (the interviewer) may not be perturbed by his asking. We may not be jolted into a defensive attitude based on the reasoning, 'I must have done something wrong if he's beginning to cross-examine me.", 10

An interviewee should also be prepared to skillfully field inadvertent illegal questions. These are questions designed to elicit information concerning race, color, ancestry, age, sex, religion, marital status, credit rating, spouse's employment, handicap, or arrest and court records not necessary for bonafide occupational requirements. Failure to cope positively and constructively with such questions can jeopardize the outcome of the interview needlessly.

\section{Interview question checklist}

What then, are the specific questions a candidate should be ready to ask? Questions will need to be tailored to reflect any knowledge gained from advance material, the work environment, job level and personal own needs. Likewise, questions will need to be addressed to the most appropriate audience. Consider carefully which questions are best asked of an individual interviewer or during a group interview session; target individual questions appropriately to a supervisor, a unit head, a colleague or peer, support staff or the director.

${ }^{10}$ Alfred Benjamin, The Helping Interview (Boston: Houghton Mifflin, 1981), 80.
A checklist of suggested queries, applicable to a variety of position levels and designed to give a point of departure, follows. Use it to create a positive and productive dialogue between you and your prospective employer. ${ }^{11}$

\section{Interview questions: A checklist}

I. Assessing direction, political climate, and administrative structure of the library.

1. What is the relationship between the library and the university?

2. What is the role of the university librarian or library director within the university community?

3 . What are the goals and objectives (philosophy) of the library?

a) Are they written? What is the process of formulation? When and how are they reviewed and revised?

b) Does the library have written policies for services provided as well as for internal functionsi.e., collection development, clientele served, etc.?

c) Does the library maintain an openness to change its philosophy?

4. What is the style of administration?

a) What system of decision making is used? Is it responsive?

b) What is the level, type and degree of staff input?

c) Does the organizational chart reflect reality?

5 . What is the library's level of participation in national, regional, and/or state programs and networks (OCLC, RLG, CLR, etc.)?

6 . What are the long range plans for the library?

a) Have there been major changes in key personnel, the administrative structure, physical facilities?

b) What major challenges has the library faced-i.e., funding, restrictions on decision making, etc.?

7. What is the relationship of the library to the community it serves? What user groups are involved-i.e., faculty, students, staff, general public?

8 . What percentage of women or minorities hold upper-level administrative positions?

${ }^{11}$ The following sources (along with the authors' personal experiences) were used in formulating the checklist. Margaret Faughnan Austin and Harriet Mason Vines, Finding Jobs and Changing Careers (New York: John Wiley \& Sons, 1983), 252-54; Ginsburg, "Preparing for Executive Position Interviews," 34-36; Michael Z. Sincoff and Robert S. Goyer, Interviewing (New York: Macmillan, 1984), 110-25; Meg Wheatley and Marcie Schorr Hirsch, "Mistakes on the Job: They Don't Always Mean You've Blown It," Ms. 14 (March 1986):18, 20; June L. Engle, Guidelines for Making a Job Decision (Chicago: ALA Hiring Subcommittee, Economic Status, Welfare and Fringe Benefits Committee, Personnel Administration Section, Library Administration Division, 1978). 


\begin{abstract}
9. Is the library centralized or decentralized?
\end{abstract}
a) How does this affect autonomy within a given unit?

b) Which functions are centralized-i.e., processing, computing operations, etc.?

c) Is the library considering new or different future organizational directions?

10. How is the unit within which the position is available viewed throughout the library?

11. What have the unit's accomplishments been to date? Is it overloaded with work or personnel?

12. What short and long term problems and opportunities exist for the library and for this particular unit?

13. What is the status of unionization/collective bargaining on campus?

a) Is the faculty organized?

b) Who is included in the bargaining unit?

c) What are the terms of the present contract?

d) What kind of input do the library and the librarians have in contract negotiations?

e) Have there been any strikes or walk-outs?

f) How strong is the union; how dedicated is the membership?

II. Assessing financial condition of the library.

1. What is the current financial situation of the library?

2. Where does the budget come from?

3 . Who controls the funds?

4. What is the solidity of that funding?

a) Does the budgeting process relate to the plans, goals, and objectives of the library?

5 . What is the prospect for improvement of the library's financial condition?

6. What is the status of outside fundraising for the library?

III. Assessing communication and position authority within the library.

1. What are the lines of communication within the organization?

a) Are they effective or ineffective; efficient or inefficient?

2 . What is the primary mechanism for communication?

a) Written or verbal? Meetings or memos?

3 . What committee structures are currently in place?

a) How long does it take to get involved in internal committee work?

\section{COLT certification}

The Council on Library/Media Technicians has formed a Certification Task Force for the exploration of the feasibility of a national certification program for library/media technicians. Anyone seeking further information may contact: COLT Certification Task Force, c/o M. Barron-SC 126, Cuyahoga Community College, Cleveland, $\mathrm{OH} 44115$.
4. Who has line versus staff authority?

5. Describe the relations between professional staff and clerical staff?

6 . Does the library have a staff development program? What levels of staffing are involved?

7. What are the advantages of working for the library? Disadvantages?

8 . How would you (the interviewer) characterize the working relationship with your immediate supervisor?

9. Is experimentation and autonomous thinking encouraged or is there "one right way" to do everything?

\section{Assessing evaluation of librarians.}

1. What is the system of evaluation for librarians?

a) Is the process peer evaluation or supervisory?

b) What kind of input does the employee have in the process?

c) How frequently are librarians evaluated?

d) Are employees allowed access to their personnel file?

e) What type of grievance procedure is available to the employee?

2. What are the criteria for promotion and/or tenure?

a) Do the librarians have faculty status? If so, what does that imply?

b) What is the standard for librariansadequacy, competency, excellence?

c) How is the standard rewarded-even salary distribution, jumps in salary between levels?

d) How is the standard measured?

3 . What is the relative weight associated with each of the following:

a) Service within the institution?

b) Publications-is release time given for writing?

c) State, regional, or national activities?

4. To what degree is merit rewarded-base adjustment or bonus?

5. What opportunities are there for advancement? Within the position? Within the library?

6. What support is there for professional development-monetary, release time, leave of absence, sabbatical, etc.?

a) What percentage of professional development opportunities are within the library vs. external programs?

7. Is there support for travel?

a) What is the mechanism for distributing these funds?

b) Is priority given to those presenting papers and/or serving on committees? Are there are any provisions for librarians new to the profession?

V. Assessing evaluation of the position.

1. Is there a current, written, well-defined job description for the position?

2 . What are the responsibilities and major challenges, rewards, stimulations of the position?

3 . Is supervision an important aspect of the posi- 
tion? What resources are provided for the position-i.e., secretarial or word processing assistance, etc.?

4. What is the perceived status of the position within the library? What are the interdepartmental and intradepartmental relationships of the position-i.e. what kinds of contacts will be made?

5. Do the librarians work with outside user groups to any extent? How does this effect the library and its services?

6 . Does the individual library or unit/area have a particular direction in which it is headed at present?

7. What period and type of training will be given for the position?

8 . What will be expected of an incumbent in the first 6 months on the job?

9 . What are the expectations of the position with regard to professional involvement, growth and development?

10. What are the current key problems and/or frustrations of the position?

11. Why is the position available? Is it newly created, a replacement, or an opening due to expansion?

12. Has any consideration been given to promoting someone from within the library?

13. If applicable, why did the previous librarian leave the position?

14. How does the supervisor operate? Does he/she delegate authority and responsibility?

15. How frequently, how regularly, and in what manner will the incumbant meet with the supervisor, and how will particular problems be handled?

16. What characteristics does the supervisor look for in a subordinate? What characteristics does the supervisor seek to avoid? Can you assess "the chemistry" between players?

17. What are the strengths and weaknesses of those supervised in this the position?

18. What are the responsibilities of the position's peer group and what are their strengths and weaknesses?

19. What limits the authority and responsibility of the position?

20. What particular aspects of the applicant's background, experience, and style are of interest to the interviewer?

a) What makes the interviewer think that the applicant would be successful?

b) Are there any areas of the applicant's background that would be a cause for concern?

c) What experience, training, attributes, operating style, accomplishments, and personality factors are sought in the "ideal" candidate?

\section{brary.}

VI. Assessing status of automation within the li-

1. Is automation taking place?

2. How will automation change the organization?

a) Are there committees composed of all levels of staff to help with the process?

3 . What is the effect of automation on staff morale?

4. Is there a need for training for all categories of users? How is the training need being met?

5. Are microcomputers available for staff use within the library? Is training provided? What software packages are currently in use?

VII. Assessing salary and benefits.

1. What is the salary range for the position? Is the salary or salary range stated? Is it negotiable? What is the salary range in the area (locale) and for peer institutions?

2 . What is included in the benefits package?

a) Is there a medical, dental, vision, and maternity plan?

b) What are the options for vacation, sick leave and personal leave?

c) What kind of life insurance and retirement benefits are included? What is the vesting schedule? What percentage represents the employer's contribution?

d) Is there a credit union affiliated with the institution?

e) What kind of tuition reimbursement or assistance and release time is available for attending classes? Where are classes available?

f) Is there an option for flexible scheduling or job sharing within the library?

g) Are there any tax incentive plans available within the institution?

h) What is the parking situation at the institution?

VIII. Assessing the community environment.

1. What cultural, recreational, religious, and entertainment activities/facilities does the community provide?

2. What is the approximate standard of living within the community: rents or housing market, groceries, utilities, taxes, etc.? Is public transportation available and frequent?

3. Is the community homogenous or is there a mix (singles, families, retirees, etc.)?

4. What is the availability and cost of health care and day care facilities within the community?

5 . What is the quality and quantity of schools and their locations within the community?

6 . What clubs and intellectual/civic organizations are available?

7. Describe typical weather conditions throughout the year.

\section{WESS discussion}

The ACRL Western European Subject Specialists Section's Membership and General Discussion Group will be held on Sunday, January 18, from 2:00 to 4:00 p.m. at the ALA Midwinter Meeting in Chicago. The topic will be: "The RLG Conoco Study: A Survey of Collecting Practices for European Materials." 


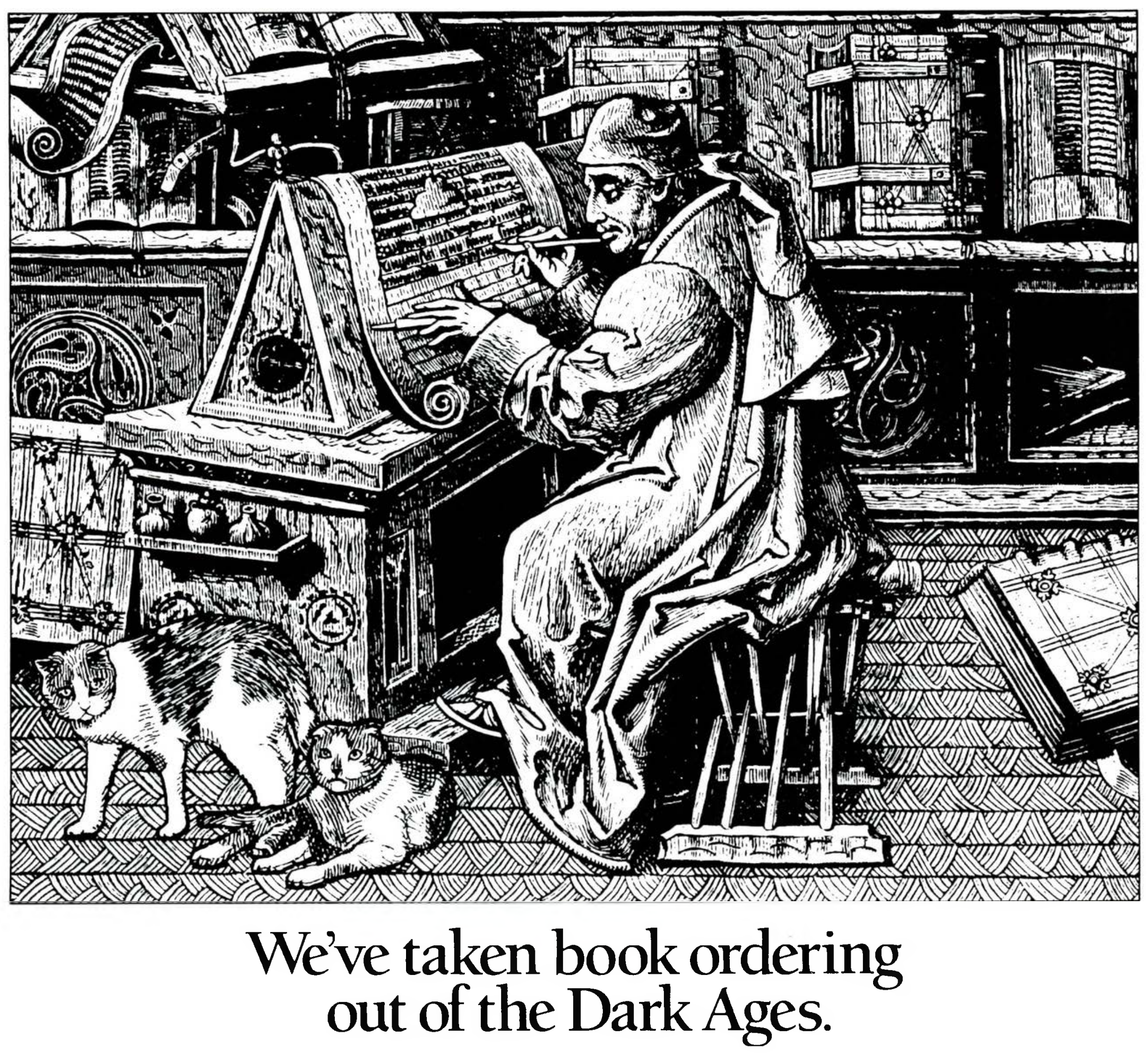

BaTaSYSTEMS ${ }^{\mathrm{m}}$ is Baker \& Tarlor's newest generation of electronic book ordering services. It's especially designed to work with existing computer hardware with built in flexibility that allows you to match the level of service to your library's unique needs.

Whichever service level you choose voull save time. reduce paperwork and speed book acquisitions-all at a lower cost. For example

ORDER allows you to order books through your personal computer, using a modem and regular telephone lines. Just enter the ISBNs and the following day youll receive electronic confimation from which you can print order slips. All calls are toll free. You also save the cost and delay of postal delivery.

Or you can choose SEARCH AND ORDER. In addition to electronic ordering, this service gives you quick access to Baker $\&$ Taylor's diverse and comprehensive database of over 800.000 title records. It's your single source for virtually all the titles published or distributed in the United States. And you eliminate manual searching and purchase order typing.

Finally. BaTaSYSTEMS ACQUISITIONS offers on-line access to our database and electronic ordering plus a complete software package with fund accounting and full reporting functions.

These advanced service technologies are typical of how Baker \& Taylor stays in step with the times. building on our experience to bring you the latest in library services.

BaTaSYSTEMS. It's nothing less than a renaissance in book acquisitions.

Write or phone today

for more information.

EXPERIENCE YOU CAN DEPEND ON

BAKER \& TAYLOR

a GRACE company

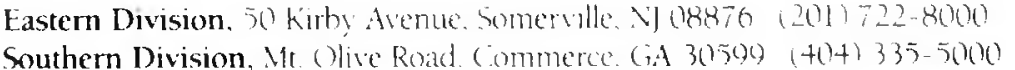

